Revista lus et Praxis, Año 26, № 2, 2020, pp. $274-295$

ISSN $0717-2877$

Universidad de Talca - Facultad de Ciencias Jurídicas y Sociales

Garantía de imparcialdiad en la Comisión para el Mercado Financiero, a propósito del procedimiento administrativo sancionador consagrado en la Ley № 21.000 Lusitania Villablanca Cerda

Trabajo recibido el 5 de diciembre de 2018 y aprobado el 23 de septiembre de 2019

\title{
Garantía de imparcialidad en la Comisión para el Mercado Financiero, a propósito del procedimiento administrativo sancionador consagrado en la Ley $\mathrm{N}^{\circ} 21.000^{*}$
}

\section{THE IMPARTIALITY GUARANTEES OF THE REGULATOR IN THE LAW N² 21.000, WHICH CREATED THE COMMISSION FOR} THE FINANCIAL MARKET

Lusitania Villablanca Cerda**

\section{RESUMEN}

En este texto se analiza la Ley № 21.000, que creó la Comisión para el Mercado Financiero respecto uno de sus dos principales objetivos: modernizar el procedimiento sancionatorio. Más precisamente, este examen concierne la garantía de imparcialidad del juzgador. Nuestra hipótesis plantea que las medidas emprendidas por la ley satisfacen en buena medida la ambición manifestada por el legislador respecto de la garantía aludida, lo que no obsta a la subsistencia de interrogantes, críticas y subsecuentes mejoras. Para ello confrontaremos el régimen de la Ley № 21.000 con el régimen existente en forma previa a la reforma y con los requerimientos han formulado respecto de esa garantía, la doctrina regulatoria, y el derecho comparado.

\section{ABSTRACT}

This text analyses Law № 21.000 that created the Commission for the Financial Market, regarding one of its two main objectives: modernizing the sanctions proceedings. More precisely, this examination concerns the court's guarantee of impartiality. Taking in account the numerous critics formulated against the former system, it was argued that the minimal procedural guarantees were not met. Our hypothesis suggests that the measures initiated by this law satisfies to a good extent the ambition expressed by the legislator regarding the alluded guarantee. This does not preclude the existence of yet to be answered questions, criticism and subsequent improvements. Therefore, we will compare it with the previously existing system and with the requirements that were formulated concerning the same guarantee by the regulatory doctrine and comparative law.

\section{PALABRAS CLAVE}

Regulación financiera; mercados financieros, CMF, Imparcialidad.

\section{KEY WORDS}

Financial markets, impartiality, financial regulators.

\footnotetext{
* Lusitania Villablanca Cerda manifiesta su agradecimiento al Sr. Matías Larraín, quien como ponente en el seminario "Procedimiento Sancionatorio Ley 21.000", de 24 de julio de 2017, organizado por el Centro de Regulación y Competencia (RegCom) se encuentra al origen de gran parte de las reflexiones contenidas en este texto

** Lusitania Villablanca Cerda, abogado, Master en derecho de los mercados, de los negocios y de la economía, Doctor en derecho. Académico Universidad Mayor, Santiago, Chile. correo electrónico: lusitania.villablanca@gmail.com.
} 


\section{Introducción}

El 23 de febrero de 2017 se publicó la Ley № 21.000 (en adelante también, "la Ley") que crea la Comisión para el Mercado Financiero (en adelante, CMF) ${ }^{1}$ en remplazo de la Superintendencia de Valores y Seguros (en adelante, SVS). Uno de los objetivos ${ }^{2}$ perseguidos por la ley era dotar al organismo de una estructura orgánica que diera garantías respecto de su despolitización y profesionalización, puesto que son precisamente esas características las que justifican la existencia de los llamados "reguladores económicos" ${ }^{3}$, y que también permiten de que se les confieran un cúmulo de facultades que no suele ser corriente en la administración estatal tradicional ${ }^{4}$.

Así, la CMF posee funciones normativas y ejecutivas que exigen el establecimiento de normas que garanticen su independencia, lo que se relaciona con el concepto de gobierno de la supervisión ${ }^{5}$. Este fue considerado por el legislador mediante la consagración de medidas tales como la colegialidad, interdicciones post empleo, participación social y lobby todas destinadas a regular los eventuales conflictos de intereses con el sector público (relacionado también con el concepto de autonomía) $)^{6}$ y con el sector privado. Ellas son analizadas en otro texto en actual redacción.

Esta vez nos concentraremos en la garantía procesal de la imparcialidad la cual, afirmamos en este texto ${ }^{7}$, es aplicable a los procedimientos sancionatorios llevados a cabo por la CMF.

Nuestro objetivo es demostrar que a la luz de las exigencias que formula la doctrina regulatoria, y las experiencias comparadas de Estados Unidos, Reino Unido y Francia ${ }^{8}$, las medidas consagradas en la Ley respecto de la imparcialidad aparecen como suficientes en varios aspectos, pero también adolecen de falencias y engendran dudas.

\section{Aplicabilidad de la imparcialidad a los procedimientos sancionatorios conducidos por reguladores económicos}

En los párrafos siguientes justificaremos la aplicabilidad a la CMF de la garantía que nos ocupa, analizando los textos normativos que se refieren a la materia.

Antes, debemos precisar que la aplicación de las garantías procesales a los procedimientos ${ }^{9}$ administrativos en general sigue siendo discutida en doctrina ${ }^{10}$. Y decimos "en general" por cuanto no existen análisis doctrinarios que se avoquen a examinar específicamente si los procedimientos

\footnotetext{
${ }^{1}$ Con fecha 13 de diciembre de 2017 se publicó en el Diario Oficial el DFL N 10 del Ministerio de Hacienda, el cual fija para el 14 de diciembre de 2017 la entrada en funcionamiento de la CMF y para el 15 de enero de 2018 la fecha de supresión de la Superintendencia de Valores y Seguros. Entre ambas fechas tuvo lugar un período de implementación. Por otra parte, el año 2019 se dictó la Ley № 21.130 que moderniza la legislación bancaria, publicada en el Diario Oficial el 12 de enero de 2019. Dicha ley incorpora dentro de la competencia de la CMF al sector bancario antes fiscalizado por la Superintendencia de Bancos e Instituciones financieras.

${ }^{2}$ En el análisis de los objetivos de esta ley obviaremos las ventajas económicas que implica tener un mercado financiero cuya regulación se ajuste a los estándares internacionales y nos atendremos a lo estrictamente jurídico. Sobre las primeras MORALES (2018), pp. 79 y ss.

${ }^{3}$ En el derecho comparado se habla de "autoridades independientes", agencias regulatorias independientes (ARI) o "reguladores independientes", FRISON-ROCHE (2011), pp. 550-559; JACOBZONE (2005), p. 92.

${ }^{4}$ GARCÍA Y VERDUGO (2009); GARCÍA (2009); LARRAÍN (2012); VILLABLANCA (2011); VILLABLANCA (2015).

${ }^{5}$ Esto es el diseño institucional del regulador, en función de los niveles de autonomía e independencia respecto del gobierno central y de la industria regulada. MASCINDARO et al. (2011), p. 4.

${ }^{6}$ CORDERO (2012b).

${ }^{7}$ El profesor Raúl Letelier afirma que para aplicar de las garantías procesales es necesaria una norma que permita inferir "que el legislador o el constituyente hayan querido aplicar ese tipo de garantías a la potestad sancionatoria administrativa". LETELIER (2017), p. 630.

${ }^{8}$ Los dos primeros elegidos como representativos del Common Law, y Francia como legislación continental bastante cercana a las tradiciones latinoamericanas.

${ }^{9}$ Sobre la diferencia entre proceso y procedimiento: FERRADA (2011).

${ }^{10}$ Exámenes sobre la materia en discusión CORDERO (2012a) y CORDERO (2014) ya las tesis citadas a continuación.
} 
llevados a cabo por los reguladores económicos ameritan un análisis diferenciado de la materia, como más adelante sostenemos que es necesario proceder.

Por tratarse de una materia latamente tratada por la doctrina, voluntariamente hemos decidido no adentrarnos en el análisis ontológico y axiológico (según la tesis que se siga) de este tema limitándonos a resumir que, en Chile, existen dos grandes tendencias doctrinarias a este respecto, más la tesis sostenida por el Tribunal Constitucional (en adelante, TC) las que pueden sistematizarse en los términos que se pasan a exponer.

Una primera tesis considera que existe una identidad material entre el poder de sanción (de la administración) y el poder de sanción de los tribunales (ya que en los dos poderes derivan de un solo y único ius puniendi estatal), por lo que se concluye que los dos poderes deben ser regidos por los mismos principios y garantías ${ }^{11}$.

Dicho argumento ha sido criticado por adolecer de un problema de insuficiencia explicativa, además de plantear una problemática que, se afirma, sería artificial ${ }^{12}$. Su origen sería el deseo de establecer mayores limitaciones a la potestad sancionatoria, para lo cual se habría recurrido a imaginar la existencia de una laguna que permitiría "la aplicación analógica del estatuto dogmático de una sanción que prima facie se le parecería (y que tiene más limitaciones) como es la sanción penal"13.

Por otra parte, nuestro TC aceptando diferenciar entre potestad sancionadora administrativa y judicial, ha afirmado la exigibilidad de las garantías: "aunque se trate de potestades que no suponen ejercicio de jurisdicción ciertamente deben sujetarse a los parámetros propios de un debido proceso"${ }^{14}$.

De esta forma, no obstante, la coherencia de aquella tesis que pugna por la diferenciación entre sanciones penales y administrativas parece ser que las posiciones que pugnan por la aplicabilidad de las garantías han ido ganando terreno a tal punto que la promulgación de esta Ley fue la oportunidad para realizar una reforma al procedimiento sancionatorio por lo menos respecto del mercado financiero.

Así quedó de manifiesto en el mensaje del proyecto de ley que creó la CMF, en cuanto pone en relieve los dos aspectos que requerían reforma:

- $\quad$ El diseño orgánico del regulador, poniendo término a la concentración de funciones ${ }^{15}$ y asegurando el debido proceso;

- $\quad$ El proceso administrativo sancionatorio de tal forma que se expliciten los principios y etapas del procedimiento aplicable ${ }^{16}$, y previendo una revisión judicial oportuna de las decisiones de la entidad regulatoria ${ }^{17}$.

Ahora bien, ¿a qué garantías nos referimos cuando hablamos de garantías procesales? Mediante esa expresión queremos hacer referencia a una serie de garantías que forman parte de lo que se denomina, derecho a un debido proceso, o proceso justo y equitativo, también denominado derecho a la tutela jurisdiccional efectiva. En general se entiende que dicho derecho está compuesto

\footnotetext{
${ }^{11}$ CAMACHO (2007), p. 17.

${ }^{12}$ Respecto a la idea del "debido proceso", Valdivia y Blake afirman que: "en términos literales ("sentencia”, "jurisdicción", "proceso"), el derecho positivo circunscribe el debido proceso al ámbito jurisdiccional, sin que se aplique directamente al terreno administrativo. Así las cosas, aunque los estándares de debido proceso no se apliquen en sentido propio fuera del ámbito judicial, se advierte cierta tendencia doctrinal y comparada a asimilarles aquellos que rigen la actividad administrativa", VALDIVIA Y BLAKE (2015), p. 121; LETELIER (2017), p. 12; CAMACHO (2007), p. 19.

${ }^{13}$ LETELIER (2017), p. 12.

${ }^{14}$ Tribunal Constitucional, Rol № 766, de 26 de junio de 2008.

${ }^{15}$ Mensaje de la Ley № 21.000 que crea la Comisión para el Mercado Financiero (en adelante “Mensaje Ley № 21.000, de 2017”), p. 4.

${ }^{16}$ Mensaje Ley № 21.000, de 2017, pp. 7 y 8

${ }^{17}$ MINISTERIO DE HACIENDA (2011), pp. 51 y 92.
} 
de varias facetas: el derecho de acceso a una justicia independiente e imparcial, el derecho a una buena justicia y el derecho a la ejecución de las decisiones de la justicia ${ }^{18}$. Como hemos señalado, en este texto nos referimos a la primera faceta.

\subsection{Consagración de la garantía de la imparcialidad}

El derecho de acceso a la justicia independiente e imparcial ${ }^{19}$ puede ser definido como el derecho de todo ciudadano a "dirigirse libremente a los tribunales para la defensa de sus intereses, aun cuando la demanda deba ser declarada irregular, inadmisible o mal fundada" ${ }^{20}$.

Se encuentra consagrado fundamentalmente en convenciones internacionales, tanto respecto de la faceta "derecho de acceso al juez", como respecto de la exigencia de que este sea "independiente e imparcial"21.

En el derecho nacional por su parte, el poder constituyente tuvo la oportunidad de consagrar la garantía del ubi ius ibi remedium estableciendo que "Toda persona puede ocurrir a los tribunales para hacer valer sus derechos y dispondrá de un recurso efectivo contra los actos que los violen", sin embargo, dicha disposición fue rechazada ${ }^{22}$. Por otra parte, si bien se consagra el derecho a no ser juzgado por comisiones especiales (sino por el tribunal que le señale la ley y que se halle establecido con anterioridad por esta), no se consagra la exigencia de que el tribunal sea independiente e imparcial.

No obstante, la falta de consagración explícita de las garantías en cuestión ${ }^{23}$, el TC ha afirmado su aplicabilidad:

todo juzgamiento debe emanar de un órgano objetivamente independiente y subjetivamente imparcial... Es más, a juicio de este Tribunal, la independencia e imparcialidad no sólo son componentes de todo proceso justo y racional, sino que, además, son elementos consustanciales al concepto mismo de juez.

\footnotetext{
${ }^{18} \mathrm{El}$ derecho a la tutela judicial “(...) tiene una doble dimensión: adjetiva y sustantiva. La primera se entiende en función de otros derechos o intereses (civiles, comerciales, laborales, etc.), mientas que la segunda es considerada por la justicia constitucional, como un "derecho fundamental autónomo, que tiene por finalidad que las personas accedan al proceso como medio ordinario de resolución de los conflictos jurídicos, lo que resulta un presupuesto mínimo de todo Estado de Derecho". Por tanto, la tutela será plena cuando se pueda accionar ante la jurisdicción, directa o indirectamente, con requisitos que permitan llegar a ella, que den una respuesta de fondo a los intereses o derechos legítimos respecto de los que se reclama y que se traduzca en una sentencia fundada y pública con la efectividad de la cosa juzgada y con garantías de su cumplimiento". GARCÍA Y CONTRERAS (2013); GUYOMAR (2001); SOTO (1998).

${ }^{19}$ Consagrado en el artículo 19 , numeral $3^{\circ}$, inciso $1^{\circ}$, de la Constitución que garantiza a todas las personas "la igual protección de la ley en el ejercicio de sus derechos", complementado con el artículo 76 inciso 10 "La facultad de conocer de las causas civiles y criminales, de resolverlas y de hacer ejecutar lo juzgado pertenece exclusivamente a los tribunales establecidos por ley".

${ }^{20}$ CORNU (2009), p. 9.

${ }^{21}$ Artículo 10 de la Declaración Universal de Derechos Humanos; Artículo 14 del Pacto Internacional de Derechos Civiles y Políticos; Declaración Americana de Derechos y Deberes del Hombre (artículo XVIII); Convención Americana sobre Derechos Humanos (artículo 8 $\mathrm{N}^{\circ} 1$ ). Respecto de la independencia e imparcialidad de aquel que juzga, ellas son planteadas como exigencias por todas las convenciones citadas, salvo la Declaración Americana de Derechos y Deberes del Hombre.

${ }^{22}$ Los señores Ortúzar, Diez y Silva Bascuñán pusieron en relieve la importancia de establecer dicha garantía, sin embargo, tras la intervención del señor Jaime Guzmán se decidió no consagrarla, "argumentándose en torno a la inconveniente y peligroso que resultaría para la autonomía de las sociedades intermedias que todo conflicto debiera derivar - necesariamente - en los tribunales de justicia", PALOMO (2002). Tribunal Constitucional, Rol N 46, de 21 de diciembre de 1987, considerando B; 1, 10; PRALUS-DUPUY (2003).

${ }^{23}$ Respecto del derecho a la tutela judicial se ha señalado que: "En primer lugar, no había -y sigue no habiendo- ninguna disposición constitucional que de manera clara reconociera un derecho de este tipo y, en segundo lugar, existía una escasa labor interpretativa por parte de nuestra doctrina y jurisprudencia constitucional sobre este derecho", BORDALí (2011). Más recientemente: "La función jurisdiccional corresponde que sea ejercida únicamente por aquellos órganos que revisten características de independencia e imparcialidad, como lo son los tribunales de justicia, y no por un órgano perteneciente a la Administración del Estado, como lo es el Servicio Nacional del Consumidor". Tribunal Constitucional, Rol N 4012-2017, de 18 de enero de 2018; "Que la Autoridad Administrativa dotada de una supuesta función jurisdiccional, no goza de la imparcialidad ni de la independencia necesarias que garanticen una verdadera resolución del conflicto", Corte Suprema, Rol № 16795, de 19 de noviembre de 2018, considerando duodécimo.
} 
Finalmente, la Corte Suprema ha señalado:

un funcionario que ejecuta parte de la potestad administrativa sin estar sujeto a los principios de imparcialidad e independencia, carece de las cualidades esenciales de un tribunal, aun cuando la ley lo nomine como tal, toda vez que no observa los elementos fundamentales que configuran la actividad jurisdiccional ${ }^{24}$.

La doctrina chilena por su parte se ha abocado poco al análisis del acceso a una justicia independiente e imparcial concentrándose en la

dimensión procesal de la justicia, es decir, se analizan las exigencias constitucionales que debe reunir el proceso y el contradictorio que se desarrolla entre partes, dejándose en un segundo plano las exigencias constitucionales de la organización de los juzgados y tribunales ${ }^{25}$.

Sin pretender paliar ese vacío doctrinario sino solo contribuir al examen de la independencia e imparcialidad aplicada a un regulador en específico, pasamos a examinar en qué consiste la garantía de la imparcialidad del juzgador aplicada a la CMF.

\subsection{Las facetas de la imparcialidad: respecto del órgano sancionador, del procedimiento aplicable y de los miembros del regulador}

La imparcialidad puede definirse como la cualidad de aquel que juzga (lato sensus) una persona, una cosa, una idea, sin tomar partido favorable o desfavorable ${ }^{26}$. Ella es aplicable a todo organismo público encargado de juzgar. Hagamos nuevamente presente que es controvertido en doctrina, el hecho de que la imposición de sanciones sea asimilable a una función jurisdiccional y que, en consecuencia, le sean aplicables las garantías procesales. Sin embargo, estimamos que la garantía de imparcialidad es sin duda aplicable a los procedimientos sancionatorios seguidos por la CMF fundados, principalmente, en los objetivos perseguidos por la ley, explicitados en su historia legislativa, y a los que ya hemos hecho referencia.

La exigibilidad de esta garantía se planteó inicialmente a propósito del cúmulo de las funciones de reglamentación y de sanción en manos de la administración estatal: ¿Cómo un organismo que dictaba normas podía también juzgar si un sujeto las había incumplido o no, sin estimarse que actuaba como juez y parte? Dicho cuestionamiento fue descartado, sosteniéndose que el cúmulo de funciones es necesario, algunos afirman que imprescindible ${ }^{27}$, para un ejercicio eficaz ${ }^{28}$ de la función regulatoria.

La pregunta que nos formulamos hoy es si es exigible a los reguladores financieros que en la aplicación de sanciones no tomen partido favorable o desfavorable.

Los análisis más recientes sobre la materia ${ }^{29}$, suelen señalar que no es posible exigir a un órgano de la administración estatal que sea imparcial respecto de la misma administración estatal

\footnotetext{
${ }^{24}$ Corte Suprema, Rol № 16795, de 19 de noviembre de 2018, considerando noveno.

${ }^{25}$ BORDALI (2009).

${ }^{26}$ ROETS (1997). También se habla de "objetividad". Sobre la relación entre ambos conceptos DOMÉNECH (2002), p. 410.

${ }^{27}$ CAMACHO (2007); ROMAN (2007); LETELIER (2017).

${ }^{28}$ BALDWIN et al. (2012); BALDWIN (1987).

${ }^{29}$ VALLEJO Y GUILOFF (inédito); LETELIER (2017).
} 
de la que forma parte ${ }^{30}$. Dicho de otra forma, no es posible pedir a un órgano de la administración (pensemos en un servicio de salud) que al aplicar una sanción (una multa a una ISAPRE, por ejemplo) no tenga un interés comprometido en el ejercicio de la función que le permite velar por el cumplimento de sus objetivos institucionales.

Nosotros consideramos que el examen de la imparcialidad de los reguladores exige realizar ciertas distinciones previas:

- La imparcialidad desde la perspectiva del órgano y del interés que tiene comprometido en el ejercicio de su facultad de sanción,

- La imparcialidad desde la perspectiva del órgano y su diseño en relación con la aplicación de sanciones,

- $\quad$ La imparcialidad de las personas naturales que juzgan el caso concreto.

\subsubsection{El interés comprometido en la facultad de sanción no es causal de parcialidad}

Como hemos adelantado, considerando el interés comprometido en el ejercicio de la facultad de sanción, se ha objetado que la Administración al sancionar estaría actuando como juez y parte. Se cuestiona entonces, la autotutela administrativa declarativa y ejecutiva.

Para contradecir el argumento anterior se ha señalado, en una opinión que compartimos, que la imparcialidad no es aplicable a la Administración desde la perspectiva del interés comprometido, puesto que la justificación del poder de sanción radica, precisamente, en que este poder es necesario para el óptimo cumplimiento de la función administrativa conferida por la Constitución al presidente de la república en colaboración con una administración técnica y profesional ${ }^{31}$.

En consecuencia, la función regulatoria en su faceta sancionadora no tendría que cumplir los estándares del derecho penal porque no se trata únicamente de

un garantismo individual frente al poder estatal de dar órdenes e imponerlas por la fuerza (el denominado poder de policía o ius puniendi estatal) sino también, y al mismo tiempo, garantismo social para la idónea satisfacción de sensibles intereses públicos comprometidos que mediante la actividad administrativa se busca salvaguardar.

Vallejo y Guiloff descartan así, calificar como jueces a los entes reguladores:

en ejercicio de sus competencias sancionadoras los órganos de la administración actúan -aunque parezca evidente decirlo- simplemente como tales, esto es como órganos del Estado dotados constitucionalmente de la responsabilidad de ejercer la función administrativa dentro de su respectivo ámbito de competencia en el marco de las cuales generalizadamente se les ha investido de potestades sancionadoras para el adecuado resguardo de los intereses públicos comprometidos.

\footnotetext{
${ }^{30}$ En Estados Unidos existe una norma referida a la independencia del regulador respecto de otros poderes políticos, pero también respecto de la opinión pública: el \$200.58 contenido en la Subpart Cel Maintenance of independence del Subpart C-Canons of Ethics del Title 17 Part 200, Chapter II, Part 200 del eCode of Federal Regulation (eCFR). Señala dicha norma: "Esta comisión (...) es una Agencia independiente y, en el desempeño de sus deberes, los miembros deben mostrar un espíritu de independencia firme y rechazar cualquier esfuerzo de los representantes de las ramas ejecutiva o legislativa del gobierno para afectar su determinación independiente de cualquier asunto que sea considerado por esta comisión. Un miembro no debe dejarse llevar por las demandas partidistas, el clamor público o las consideraciones de popularidad o notoriedad personal; así también él debería estar por encima del miedo a las críticas injustas de cualquiera".

${ }^{31}$ VALLEJO Y GUILOFF (inédito).
} 
En consecuencia, "una vez depuesta la noción de que la administración actuaria "como juez" puede descartarse que actúe como parte cuando ejerce potestades sancionatorias".

Por otra parte, un reciente fallo de la Corte Suprema señaló que no debe "olvidarse que la autoridad administrativa, aun cumpliendo supuestas funciones jurisdiccionales otorgadas por el legislador, sigue estando funcionalmente destinada, al menos, a satisfacer el fin de interés general perseguido por el Estado" ${ }^{32}$. El fallo no contradice lo que hemos sostenido porque él está referido a las facultades de arbitraje conferidas a un regulador, es decir, a la facultad para dirimir conflictos de terceros (a nuestro parecer equivalente a un juez civil), la que no obedece a la misma lógica de los procedimientos sancionatorios (a nuestro parecer equivalentes a un procedimiento ante un tribunal penal).

En suma, desde la perspectiva del interés comprometido en la facultad de sanción nos. Parece que la imparcialidad no puede ser exigida regulador puesto que dicho poder se le confiere para cumplir su objetivo estatutario: proteger el mercado. Pensar de otra manera equivale a pedir a los tribunales que sean imparciales respecto de su interés en administrar correctamente justicia.

Veamos qué sucede con la imparcialidad respecto de la organización del procedimiento de sanción.

\subsubsection{Imparcialidad: separación de la instrucción y el juzgamiento y la estructura del regulador}

Lo que la doctrina administrativista nacional no ha analizado específicamente, es la aplicabilidad de la garantía de la imparcialidad en la organización del procedimiento de sanción en el sentido en que esta exige la separación entre las funciones de investigar o fiscalizar (asimilable a la instrucción en el procedimiento penal) y la función de juzgamiento.

En este punto la noción de garantismo social no nos parece suficiente para descartar la aplicación de la garantía de imparcialidad al diseño orgánico del regulador, pues este también debe asegurar aquella parte mínima de garantismo individual de la que no puede prescindirse en el ejercicio del poder de sanción.

Al respecto, mirando al derecho comparado la imparcialidad se consagra operando una separación entre las funciones de investigar o fiscalizar y la función de juzgamiento ${ }^{33}$, llegando incluso a exigirse que ambas funciones estén radicadas en organismos funcionalmente separados ${ }^{34}$. En la búsqueda de dicha imparcialidad orgánica, en Inglaterra, tras los cambios introducidos por la Financial Services Act (FSA) de 2012, los poderes de la antigua FSA fueron repartidos entre la Financial Conduct Authority (FCA) y la Prudential Regulation Authority (PRA), siendo la primera quien ejerce los poderes antes detentados por la antigua Financial Services Authority ${ }^{35}$.

\footnotetext{
${ }^{32}$ Corte Suprema, Rol № 16795, de 19 de noviembre de 2018, considerando décimosegundo.

33 "La función de acusación debe ser atribuida a un órgano distinto de juez". DE LA OLIVA et al. (1999), p. 43. En cuanto a los orígenes de esta garantía: RODRÍGUEZ (2013).

${ }^{34}$ Para mayor ilustración distinción podemos recurrir a la distinción realizada por la profesora francesa Frison-Roche quien distingue la imparcialidad personal (que atiende a la persona que juzga) de la imparcialidad estructural (que atiende a la organización de la institución que juzga). De esta primera distinción se cruza una segunda que distinguen entre la imparcialidad subjetiva (que concierne el fuero interno del juez y que le impide tener un interés en el litigio) de la imparcialidad objetiva (que impide que la posición del órgano juzgador cree una situación de prejuzgamiento). La imparcialidad concierne así 4 hipótesis y la que concierne directamente a las autoridades es la imparcialidad estructural objetiva. FRISON-ROCHE (2010).

${ }_{35}$ PART 19, The Regulators, CHAPTER 1, 1A, (1): "The body corporate previously known as the Financial Services Authority is renamed as the Financial Conduct Authority". Ver también PART 2 Amendments of Financial Services and Markets Act 2000, Official listing 16. FCA to exercise functions under Part 6 of FSMA 2000, Suspension and removal of financial instruments from trading, 36. Suspension and removal of financial instruments from trading.
} 
Los procedimientos difieren según la infracción y sanción aplicable, por ejemplo, tratándose de una violación a las reglas sobre transparencia en la cotización de valores, prevista en el artículo 89 de la FSA, si la autoridad (FCA o PRA) decide tomar medidas ella debe realizar una advertencia e indicar el monto de la sanción que se propone al Tribunal de servicios y mercados financieros (Financial services and markets Tribunal) ${ }^{36}$.

En el caso del modelo francés, se establece un Colegio, cuerpo colegiado, valga la redundancia, órgano ejecutivo del regulador (la Autoridad de los mercados financieros, AMF), y por otra parte se encuentra otro cuerpo colegiado denominado Comisión de Sanciones. La apertura del procedimiento y su instrucción, se encuentran en manos de un relator miembro de la Comisión de Sanciones, siendo esta última quien decide si se aplica una sanción o no ${ }^{37}$.

Destacamos como medidas destinadas a asegurar la separación orgánica entre el Colegio y la Comisión ${ }^{38}$ las siguientes:

- Un representante del Colegio puede intervenir delante de la Comisión de Sanciones ${ }^{39}$, desde la notificación de los cargos, pudiendo ser escuchado en audición, teniendo derecho a acceder al expediente, a plantear observaciones escritas y proponer una sanción ${ }^{40}$. Estas modificaciones tuvieron por objeto evitar que sea el relator (miembro de la Comisión de Sanciones) quien proponga una sanción ${ }^{41}$.

- $\quad$ Ni el relator, ni el representante del Colegio pueden participar en la deliberación final.

- Demostrando a nuestro parece, la completa separación de funciones, el Colegio puede apelar de las decisiones de la Comisión de Sanciones.

En Estados Unidos el regulador, la Securities and Exchange Commission investiga a través de su división de Enforcement, y cuando decide acusar debe llevar las causas antes las cortes de distrito o bien su propio tribunal administrativo, organismo independiente de los miembros de la Comisión. También se encuentra habilitada para apelar de la decisión de los tribunales.

De esta forma, dos importantes legislaciones han cuidado de separar completamente las funciones de investigación y formulación de cargos y de actividad sancionadora propiamente tal, radicándolas en órganos separados.

En el mismo sentido han operado en Chile la reforma en materia de libre competencia, mediante la creación de la división entre la Fiscalía Nacional Económica y los Tribunales de la Libre Competencia ${ }^{42}$, y en materia medioambiental, mediante la separación entre la Superintendencia del Medioambiente y los Tribunales Ambientales.

\subsubsection{Imparcialidad de las personas naturales que juzgan}

Hemos afirmado que, al regulador, como órgano estatal, no puede exigírsele que sea imparcial respecto de interés que se le encarga como objetivo institucional, sin embargo,

\footnotetext{
${ }^{36}$ Part VI de la FSAA, artículo 91, № 3.

${ }^{37}$ Hay que destacar que, según el Tribunal Europeo de Derechos Humanos, "Si el cúmulo de funciones de instrucción y de juzgamiento no es en sí incompatible con el respeto de la imparcialidad, está subordinado a la ausencia de un "prejuzgamiento" por parte de la Comisión". Tribunal europeo de derechos humanos, Dubuis SA c/ France, 11 de junio de 2009. FRISON-ROCHE (2009), p. 501.

${ }^{38}$ LASSERRE (2010).

${ }^{39}$ Décret $\mathrm{N}^{\circ} 2008-293$, de 2 de septiembre de 2008, lo que ha no ha estado exento de crítica por parte de la doctrina. ANGEL Y DEZEUSE (2008).

${ }^{40}$ DUFOUR (2010), p. 5; LASSERRE (2010), p. 16.

${ }^{41}$ Cour d'appel de Paris, 25 junio de 2008. Los profesionales criticaban la tendencia del miembro relator a proponer sanciones: GONTARD (2010), pp. 5-6.

${ }^{42} \mathrm{Si}$ bien es controvertible que se trate de tribunales, no se puede discutir que existe una separación entre quien instruye y quien decide.
} 
consideramos que dicho análisis no es replicable respecto de las personas "físicas", como las denomina el profesor Domenech ${ }^{43}$, que integran el regulador.

Esa exigencia se traduce en la obligación de abstención consagrado en el artículo 12 de la Ley 19.880, de 2003 (en adelante, LBPA) y respecto del cual se ha señalado: "Dicha obligación se establece en relación con situaciones o procedimientos concretos de los cuales les corresponda conocer o decidir, oportunidad en la cual deberá ser analizada la procedencia de dar debido acatamiento a esa obligación" ${ }^{44}$.

En Francia la Ley № 2017-55 sobre el estatuto general de las autoridades administrativas independientes y las autoridades independientes establece en el artículo 12, entre otras, que ningún miembro de esos organismos puede participar en una sesión, deliberación, verificación ni control:

- Cuando se encuentra en una situación de conflicto de interés entendiendo por tal "toda situación de interferencia entre un interés público e intereses públicos o privados que por su naturaleza pueda influir o parezca influir el ejercicio independiente imparcial y objetivo de una función. Dicha causal se aplica también cuando dicho interés ha existido dentro de los 3 años que preceden la deliberación, la verificación o el control.

- Cuando ejerce funciones o mandatos en relación con una persona jurídica concernida por la deliberación verificación o control o los ha ejercido en el curso de los 3 años que las preceden.

En Estados Unidos el título 17 del e-CRF relativo a la Commodity Futures Trading Commission y a la Securities and Exchange Commission contiene normas generales (estándares) relativos a la imparcialidad de los reguladores. En dicha normativa se evoca la imparcialidad bajo la denominación de perspectiva independiente (Independent perspective) entendiendo por tal un punto de vista imparcial respecto de los asuntos que conciernen la competencia, el negocio o la industria de manera que la decisión considera a todos los grupos interesados que están involucrados. Se establece así, que los miembros deben mantener estándares inusualmente altos de honestidad, integridad, imparcialidad y conducta. Deben estar constantemente conscientes de la necesidad de evitar situaciones de las que pueda resultar una mala conducta, o un conflicto de interés ya sea real o aparente (justice must be seen to be done) ${ }^{45}$. En todo hay que tener presente que normalmente la SEC no aplica sanciones, sino que estas quedan en manos de jueces administrativos, cuya conducta, especialmente la "deferencia con el regulador", también ha sido objeto de controversias ${ }^{46}$.

\section{Imparcialidad en la Ley № 21.000: separación de la instrucción y el juzgamiento e imparcialidad de los miembros del regulador}

En esta sección examinaremos el tratamiento de la imparcialidad dado en la Ley desde la perspectiva del diseño del órgano y de las personas naturales que juzgan el caso concreto.

\footnotetext{
${ }^{43}$ DOMÉNECH (2002), p. 409.

${ }^{44}$ VALPUESTA Y PÉREZ (2012); Dictamen CGR, № 39.453, de 15 de julio de 2010.

${ }^{45}$ Se establecen normas en 5 CFR parte 2635 (empleados del poder ejecutivo), 5 CFR parte 4401, §200.735-2 Subpart M, subparte C de esta parte 200 (miembros de la Comisión de Bolsa y Valores). El must be seen to be done se aproxima al concepto de imparcialidad "aparente", esto es que no solo es necesario que no exista un conflicto de interés, sino que además, no debe siquiera generarse la apariencia de un conflicto. En ese sentido la OCDE en la "Guía para crear una cultura de independencia", señala en el punto 4.4, "Normas sobre conflicto de interés", que "El profesionalismo e integridad de los directivos deberán protegerse a través de medidas para evitar influencias indebidas ya sean percibidas o reales", OCDE (2017).

${ }^{46}$ Ver por ejemplo la solicitud presentada por los cinco Comisionados de la SEC en la que pidieron a un Juez de Derecho Administrativo que presentara una declaración jurada que indicara si alguna vez ha experimentado una presión para decidir a favor de la SEC. SECURITIES AND EXCHANGE COMMISSION (2015).
} 


\subsection{Imparcialidad de los miembros del regulador o imparcialidad personal}

Como hemos señalado, la garantía de imparcialidad se traduce, respecto de las personas físicas, en el deber de abstención de los miembros que se encuentran en situación de conflicto de interés que les impide pronunciarse sin el riesgo de tomar partido favorable o desfavorable. Hagamos presente que también existen interdicciones post empleo que buscan evitar el conflicto de interés, sin embargo, no las analizaremos puesto que ellas solo actúan como contraincentivo y con carácter ex post, de tal forma que, por su propia naturaleza (futura), no puede ser invocadas por un sujeto regulado que está siendo objeto de un procedimiento de sanción ${ }^{47}$.

La materia fue tratada: a) consagrando causales de abstención nuevas en el artículo 16 de la Ley № 21.000; b) remitiéndose a la ley de probidad (Art. 2 y 16 № 2 y 3); y, c) remitiéndose a la LBPA, así como a los deberes generales de abstención para el ejercicio de la función pública establecidos en otras leyes (Art. 16 inc. 30). En los párrafos siguientes nos haremos cargo de ellos concentrándonos particularmente, por razones obvias, en las nuevas causales de abstención.

\subsubsection{Normas de probidad y su vínculo con el deber de abstención de la LBPA}

La probidad en la función pública se define en el Art. 1 inciso 2ㅇ de la ley de probidad como un principio conforme al cual debe observarse "una conducta funcionaria intachable, un desempeño honesto y leal de la función o cargo con preeminencia del interés general sobre el particular".

La remisión a la ley de probidad y la LBPA carece de relevancia por cuanto ya vinculaban a la SVS en virtud del ámbito de aplicación señalado por los mismos textos normativos (Art. 4 № 1 de la ley de probidad, y 2 inciso primero de la LBPA).

La ley de probidad parte del supuesto de que la ciudadanía, debidamente informada en base a los mecanismos que ella provee, es la mejor situada para controlar los conflictos de interés que afecten a funcionarios públicos ${ }^{48}$. Se entiende también que la libre disponibilidad de esa información actuaría "como un contraincentivo respecto de conductas abusivas"49; los sujetos por el solo hecho de estar obligados a proporcionar información, se verían compelidos a actuar en regla con la normativa.

Por ello se obliga a ciertos funcionarios a efectuar una declaración de intereses y patrimonio.

Precisemos, la utilidad de la ley de probidad es potencial ${ }^{50}$ porque ella radica en proporcionar la información necesaria para verificar en qué casos un funcionario tiene un "interés comprometido". Dicha información es necesaria, por ejemplo, para fiscalizar el cumplimiento de la obligación de abstención, prevista en el Art. 12 LBPA, al que por razones de extensión nos remitimos, sin reproducirlo. Dado el perímetro regulatorio en que los comisionados se desempeñan, son útiles las obligaciones de declarar (artículo 7):

\footnotetext{
${ }^{47}$ Podríamos pensar en un sujeto regulado sancionado que, luego de un tiempo, percibe que entre los comisionados que tomaron la decisión de sanción se encontraba uno que, tras el término de sus funciones, se desempeña para una entidad que puede calificarse como parte de su competencia en el mercado. De haberse respetado la interdicción post empleo no podría formularse reproche alguno.

48 “(...) en un régimen democrático el mejor ente fiscalizador del principio de probidad es, en último término, la propia ciudadanía la que tiene los mayores incentivos para denunciar y perseguir actos de corrupción. Esa es la razón por la cual este gobierno, ante diversas opciones legislativas, optó por aquella que genera mayores espacios para empoderar el denominado "control ciudadano"'”. Mensaje de la Ley № 20.880, de 2015, p. 4.

${ }^{49}$ Mensaje de la Ley № 20.880, de 2015, p. 4.

${ }^{50}$ Calificamos de "potencial" la utilidad de la ley por cuanto nuestra ciudadanía que aún sabe poco y ejerce menos su rol de vigilante de la probidad funcionaria.
} 
- Las actividades profesionales, laborales, económicas, gremiales o de beneficencia, sean o no remuneradas. Se deben declarar no solo las actividades actuales, sino también las realizadas en los doce meses anteriores a la fecha de asunción del cargo porque, como hemos comentado con anterioridad, el conflicto de interés con el sector privado proviene normalmente de las actividades profesionales previas al desempeño del cargo.

- $\quad$ La posesión de valores sometidos a oferta pública.

- El nombre completo de sus parientes por consanguinidad en toda la línea recta que se encuentren vivos y en el segundo grado tanto en la línea colateral como por afinidad.

- Los bienes del cónyuge y los del conviviente civil cuando estén en un régimen de comunidad de bienes. Si el régimen es otro la declaración es voluntaria y requiere el consentimiento del propietario. Lo mismo, si la cónyuge del declarante es titular de un patrimonio reservado.

No nos parece acertado que la declaración de las actividades profesionales, laborales, etc. se restrinjan a un período de 12 meses considerando que la obligación de abstención concierne relaciones de profesionales que hayan tenido lugar en los últimos dos años. En la misma línea habría sido saludable extender la obligación de abstención a los últimos 3 años, como hemos citado respecto del caso francés. Finalmente, nos parece erróneo haber regulado las declaraciones en función del régimen patrimonial pactado, por cuanto es evidente que, independiente de este régimen, cualquier medida adoptada por el funcionario y que favorezca a su cónyuge o conviviente civil, lo posicionaría en una situación de conflicto de interés ${ }^{51}$. Entendemos que debió seguirse la misma lógica que, en el mismo artículo obliga a declarar las actividades económicas, profesionales o laborales que conozca, de su cónyuge o conviviente civil, cualquiera sea el régimen pactado.

En resumen, más allá de remitirse a cuerpo legales que ya eran aplicables a la SVS, la Ley no estableció nuevos mecanismos destinados a evitar el conflicto de intereses durante el ejercicio de las funciones, radicando la verdadera novedad en el Art. 16 de la Ley.

\subsubsection{Las nuevas causales de abstención consagradas en el artículo 16 de la Ley № 21.000}

El artículo 16 de la Ley señala que los comisionados deberán abstenerse de participar y votar cuando se traten materias o se resuelvan asuntos en que puedan tener interés expresando también las circunstancias bajo las cuales este se configura. Comienza por una cláusula de apertura, muy bienvenida, a través de la cual se deja abierta la posibilidad de que existan otras circunstancias en las que existe interés comprometido. En cuanto a las causales solo queremos destacar las siguientes:

1. Cuando las decisiones o asuntos a tratar recaigan sobre sociedades o entidades en las que se hubiere desempeñado en los últimos doce meses como director, administrador, gerente,

\footnotetext{
${ }^{51}$ Cuando en el diseño de las causales de inhabilidad se recurre a principios o estándares generales complementados con normas formales se da pie para entender que, si una situación jurídica concreta no se encuentra subsumida en la hipótesis formal, tenemos que excluirla también del estándar. V. a modo de ejemplo el Dictamen CGR, № 58.558, de 24 de noviembre de 2012: “(...) esa entidad edilicia expone, en síntesis, que el nombramiento en el cargo por el cual se reclama se ajustó a la normativa vigente, toda vez que, si bien el servidor designado es el padre de la nieta de la máxima autoridad, no existe ni ha existido matrimonio civil de aquel con la hija del alcalde, por lo que no se configura la causal de inhabilidad relacionada con el parentesco contemplada en la ley". A lo anterior la CGR replicó: "el Art. 12 de la ley № 19.880 (...) previene, en su numeral 1, en lo que interesa, que deben abstenerse de intervenir en el procedimiento respectivo las autoridades y funcionarios de la Administración que tengan interés personal en el asunto de que se trate o en otro en cuya resolución pudiera influir la de aquel. (...) de la documentación tenida a la vista -y tal como, por lo demás, se expresa en el informe municipal citado-, consta que la indicada autoridad edilicia, al momento de resolver el certamen, era el abuelo de la hija del funcionario seleccionado. (...) se colige que esa circunstancia comprometió la imparcialidad con la que debió actuar el alcalde en la decisión del proceso de selección, procediendo que se hubiera inhabilitado de intervenir en cualquier acto que se relacionara con este (....)", VALPUESTA (2013), p. 147.
} 
trabajador dependiente o asesor, consejero o mandatario, ejecutivo principal o miembro de algún comité, como también de sus matrices, filiales o coligadas. En este caso la ley no señala expresamente si deben tratarse de actividades remuneradas o no, omisión que también contiene la LBPA, en cualquier caso, en ambas circunstancias deben ser declaradas conforme al Art. 7 de la ley de probidad.

Observemos que la última causal solo se extiende a relaciones que hayan tenido lugar en los últimos doce meses, sin embargo, como ellas parecen estar comprendidas en el № 5 del Art. 12 de la LBPA, la prohibición debería extenderse, por aplicación de esta última ley, a dos años.

2. Cuando se haya pronunciado o emitido opiniones, por cualquier medio, sobre un procedimiento sancionatorio en curso y cuya resolución se encontrare pendiente. Volveremos sobre este numeral en el apartado siguiente en relación con presunción de inocencia y la prohibición de un prejuzgamiento.

El Consejo reguló los procedimientos y mecanismos que deberán adoptarse en materia de conflictos de interés en tan solo dos artículos: el Art. 19 (información sobre deberes en materia de probidad administrativa y conflictos de interés) y 20 (Principio y procedimiento de abstención) de la Resolución Exenta № 02 de 21 de diciembre de 2017. Solo nos parece destacable que se haya previsto que el Área jurídica, la División Jurídica y la Secretaría General les debe prestar asistencia y mantener a los comisionados debidamente informados acerca de los deberes que les asisten en la materia. Lo anterior, en consonancia con la Recomendación (№8) del Consejo de la OCDE sobre integridad pública del año 2003.

Como se permite al comisionado afectado asistir a la sesión aún cuando se traten materias adicionales a aquella que lo implica, la Ley tuvo que precisar que su asistencia no será considerada para los efectos de determinar el quórum necesario para la resolución de la materia o asunto en la que pudiera tener interés o estar involucrado.

Destaquemos que, a nuestro parecer las causales de abstención también son aplicables al ejercicio de las medidas de policía ${ }^{52}$, quedando únicamente excluidas del deber de abstención, las facultades normativas según precisa el numeral 3 de la norma:

Sin embargo, dicha prohibición no impedirá que el comisionado afectado pueda participar de las decisiones que tengan por objeto dictar normas de alcance general y que resulten aplicables a un sector, mercado o industria. Lo anterior, sin perjuicio de los deberes generales de abstención para el ejercicio de la función pública.

Entendemos que cuando se configuran causales de abstención distintas a los vínculos a que se refiere el numeral 3 del Art. 16, no se permite el ejercicio de facultades normativas; esa interpretación encuentra su fundamento en el hecho de que el numeral 4 lo señaló de forma específica para él, y que se haya agregado que esa excepción es "sin perjuicio de los deberes generales de abstención para el ejercicio de la función pública".

A modo de conclusión, nos parece particularmente relevante que la ley no haya restringido las causales en que existe conflicto de interés de manera taxativa, lo que permitiría salvar la incongruencia existente entre los plazos que debe abarcar la declaración de intereses (12 meses) en relación con el deber de abstención ( 2 años), así como considerar que existe conflicto de interés aún cuando la situación que lo origina sea anterior al plazo de dos años. Admitimos que la interpretación es discutible al existir normas expresas que regulan la materia. Igualmente hemos detectado una

\footnotetext{
${ }^{52}$ Estas son asimilables a las medidas sancionatorias; de hecho, algunas son idénticas, diferenciándose únicamente por sus objetivos: preventivo o sancionatorio. Volveremos sobre el tema en el punto 3.2.1.
} 
incongruencia al haber limitado ciertas declaraciones de intereses según el régimen matrimonial pactado.

Corresponde ahora analizar el tratamiento de la imparcialidad desde el punto de vista del órgano juzgador.

\subsection{El diseño del organismo regulador en relación con las etapas de instrucción y juzgamiento}

Hemos dicho que la Ley № 21.000 se articuló en torno a dos grandes ejes: la modernización del gobierno de la supervisión (estructura del regulador) y del procedimiento sancionador. Sin embargo, están íntimamente conectados puesto que la separación entre las personas que ejercen la función de instrucción y las que ejercen la función de juzgamiento implica una reforma del procedimiento sancionador.

La Ley № 21.000 diseñó la Comisión para el Mercado Financiero previendo que la dirección superior de ella la estaría a cargo del Consejo de la CMF (artículo 8), el cual ejerce la facultad sancionatoria.

Para fortalecer la garantía de imparcialidad se separaron las funciones de instrucción y juzgamiento entregando la instrucción y el levantamiento de $\operatorname{cargos}^{53}$ a una unidad de investigación (Título I, párrafo 3). Llama, en todo caso, la atención que el fiscal sea nombrado por el Consejo, órgano que sanciona, aun cuando lo sea mediante el proceso de selección de alta dirección pública. Vemos ahí un punto controversial y que, en el derecho norteamericano y francés, no se plantea.

Siguiendo las líneas generales del derecho comparado ${ }^{54}$, se encomendó al Consejo ${ }^{55}$, la aplicación de sanciones y la autorización de las medidas de policía, así como de las medidas intrusivas.

No se puede desconocer los méritos de la reforma, sin embargo, podemos concebir ciertas situaciones que aún con el nuevo diseño pueden resucitar el fantasma de la parcialidad; nos referimos a la aplicación de las medidas de policía e intrusivas, al quórum para la aplicación de sanciones, y al hecho de que el fiscal y el Consejo convivan bajo una misma personalidad jurídica, las que pasamos a describir.

\subsubsection{Medidas intrusivas y de policía en relación con la prohibición de un prejuzgamiento}

Dentro de las facultades que permiten a los reguladores cumplir la misión que la ley les encomienda se encuentran las medidas de policía y las medidas intrusivas. Las primeras no tienen naturaleza represiva, sino preventiva, por cuanto su objetivo es únicamente proteger el orden público y el respecto de ciertas normas mínimas que organizan el ejercicio de una actividad ${ }^{56}$. Se caracterizan por el hecho de que su aplicación no depende necesariamente del comportamiento del actor en cuestión, por lo cual son menos estigmatizaste para el sujeto o entidad a la que se le aplica. No obstante, para ser implementadas se requiere necesariamente que el regulador emita un pronunciamiento, a veces de provisorio, sobre la legitimidad de una situación o conducta, lo que es relevante porque la situación que motiva la aplicación de estas medidas puede dar, finalmente, lugar a una sanción.

\footnotetext{
53 Párrafo 3 de la Ley № 21.000, de 2017, Unidad de Investigación.

${ }^{54}$ Una alternativa al diseño anterior podría haber sido la de crear un tribunal separado, un Tribunal de Valores y Seguros; LARRAIN (2012).

${ }_{55}^{5}$ Título II, artículo 8, y párrafo 1 de la Ley № 21.000, de 2017.

${ }^{56}$ PRALUS-DUPUY (2003), p. 557.
} 
Tal situación puede tener lugar a propósito de las facultades consagradas en los artículos 14 y 36 de la Ley № 18.045, de Mercado de Valores. En virtud de la primera de las normas citadas, se pueden suspender las transacciones de un valor de oferta pública si así lo requiere el interés público o la protección de los inversionistas ${ }^{57}$. Cuando las circunstancias que justificaron dicha medida se mantienen, se debe proceder a cancelar la inscripción en el Registro de Valores. En el artículo 36 por su parte, se confiere la facultad de suspender la inscripción de un corredor de bolsa o de un agente de valores cuando se han dejado de cumplir, incluso temporalmente, con los requisitos necesarios para la inscripción. Dicha situación puede ocurrir, a modo de ejemplo, cuando disminuye el patrimonio mínimo exigido a los corredores, o cuando tiene lugar un procedimiento concursal. Notemos que ninguna de estas situaciones constituye por sí misma una infracción; se trata simplemente del incumplimiento de un requisito establecido por la ley para figurar en un registro.

El procedimiento a través del cual se toman las medidas de policía puede dar lugar a controversias cuando los hechos que dieron lugar a ellas sean finalmente constitutivos de una infracción que deba ser sancionada. Ello porque su ejercicio recae en el presidente de la Comisión, al que se le confiere incluso la facultad más genérica de

adoptar, en general, cualquier medida preventiva o correctiva que disponga la ley, en los casos en que no se cumpla con las normas necesarias para el adecuado desarrollo de tales actividades o cuando así lo requiera el interés público o la protección de los inversionistas. Posteriormente a la adopción de dichas medidas, el presidente debe informar al Consejo quien deberá pronunciarse sobre la conveniencia de mantenerla o dejarla sin efecto ${ }^{58}$.

En función de lo anterior y dados los quórums de funcionamiento del Consejo, esas medidas deben ser autorizadas con la asistencia de 3 miembros y el voto favorable de dos de ellos, uno de los cuales sería el presidente que autorizó inicialmente la medida. De esta forma, si los hechos llegan a ser objeto de una sanción, el pronunciamiento anterior de los comisionados (al autorizar la medida de policía) puede ser interpretado como un prejuzgamiento y generar dos tipos de cuestionamientos: respecto de la imparcialidad del Consejo y respecto de la presunción de inocencia.

En cuanto a las medidas intrusivas ellas son enumeradas por el № 27 del Art. 5 de la Ley № 21.000 las que no reproducimos por razones de extención. Las medidas son ejercidas por el fiscal, debiendo contar con el voto favorable de a lo menos tres comisionados y además con la autorización de un ministro de la Corte de Apelaciones de Santiago.

El problema que percibimos es que, tras la instrucción correspondiente, el fiscal podrá formular una acusación cuya sanción deberá ser resuelta por el Consejo, cuya mayoría habrá ya manifestado su opinión sobre la situación al momento de autorizar la medida.

La reglamentación de las medidas de policía e intrusivas genera una situación particularmente delicada porque el artículo 16 № 4 de la ley prevé como causal genérica de abstención en un determinado asunto (no necesariamente en un procedimiento sancionatorio) cuando se traten materias o se resuelvan asuntos en que los comisionados puedan tener interés y, se entiende que el comisionado tiene interés, entre otras circunstancias, cuando se haya pronunciado o emitido opiniones, por cualquier medio, sobre un procedimiento sancionatorio en

\footnotetext{
${ }^{57}$ Por ejemplo, la Resolución SVS, N 322, de 9 de junio de 2011, suspendió la cotización de las acciones de Empresas La Polar S.A., en razón de un hecho esencial enviado por la sociedad, ya que se estimó que la información proporcionada por la compañía requería de un periodo razonable de difusión y análisis por parte del mercado, de los accionistas e inversionistas.

${ }^{58}$ Artículo 21 № 5 de la Ley № 21.000, de 2017.
} 
curso y cuya resolución se encontrare pendiente. Hagamos presente que la norma no exige que la opinión se haya emitido durante la instrucción del procedimiento, por lo que entendemos que se configura la causal cuando, incluso antes de la apertura del procedimiento sancionatorio existió opinión previa sobre hechos que sean finalmente objeto de un procedimiento de sanción.

Dejemos claro que no se trata de una simple especulación, una situación similar tuvo lugar en Francia, en el año 2009 a propósito del conocido como caso EADS. En tal caso, el regulador financiero autorizó que se ejerciera una medida bastante menos gravosa que las que hemos descrito en los párrafos anteriores; nos referimos a la medida de "Advertencia Inmediata", en la cual el regulador hace pública la existencia de una investigación contra un agente regulado a fin de que los consumidores de productos financieros tomen sus decisiones de inversión. En ese caso, con ocasión de la aplicación de una sanción, se estimó que la autoridad había prejuzgado dicha situación al momento de autorizar el ejercicio de la medida de policía ${ }^{59}$.

Este tipo de situaciones muestran cómo pueden llegar a enfrentarse garantías igual de legítimas: la imparcialidad del juzgador en oposición a la reactividad o celeridad que exige la función regulatoria frente a situaciones de riesgo.

Lo anterior pone en evidencia la importancia de separar aún más las funciones al interior de los organismos regulatorios, lo que lamentablemente exige un cambio legislativo, puesto que la ley señala expresamente quienes tienen competencia para el pronunciamiento/autorización de medidas de policía o intrusivas, de otra manera la objeción podría haberse salvado poniendo la decisión a cargo únicamente del fiscal, de un superintendente, o únicamente del presidente de la Comisión u otro miembro del Consejo, el que debería luego abstenerse de tomar parte en la decisión de sanción ${ }^{60}$.

La reforma antes descrita nos parece imprescindible para dar cumplimiento a los objetivos manifestados en el mensaje de la Ley en la búsqueda de la imparcialidad: el Consejo decidiría la aplicación de sanciones, "sin que este intervenga de modo alguno en el proceso previo de investigación de las infracciones detectadas" ${ }^{61}$.

\subsubsection{Quorum para la aplicación de sanciones y legalidad del tribunal}

El Art. 52 de la Ley № 21.000 establece que el quórum necesario para decidir la aplicación de una sanción es el de la mayoría de los consejeros presentes en la sesión. En relación con la garantía de legalidad del tribunal, que en este caso está constituido por el Consejo para el Mercado Financiero, nos parece que dicho quórum debió definirse en relación con la totalidad de los integrantes de dicho Consejo.

Para la debida comprensión de la afirmación anterior recordemos que conforme al artículo 9 de la Ley el Consejo se encuentra integrado por 5 consejeros, y que según el artículo 15 el quorum de funcionamiento es de tres de sus miembros. Los acuerdos, por su parte, deben ser adoptados por mayoría absoluta de los comisionados presentes, salvo que la ley exija una mayoría diferente. El artículo 52 por su parte señala que el Consejo pondrá término al procedimiento sancionatorio

\footnotetext{
${ }^{59}$ AMF (2009).

${ }^{60}$ En todo caso, parte de la doctrina estimó que la situación de vulneración de la garantía podía ser teóricamente salvada por el hecho de existir un recurso jurisdiccional de "plena jurisdicción" IDOUX (2010), p. 926. Sin embargo, ello se traduce en que necesariamente habría que pasar por la decisión de los tribunales ordinarios.

${ }^{61}$ Mensaje Ley № 21.000, de 2017, p. 6.
} 
mediante resolución fundada adoptada por la mayoría de los miembros presentes. Esto se traduce en que la decisión de sanción podría dictarse con un quorum mínimo de $2 / 5^{62}$.

Si tal fuera el caso, la legitimidad de la sanción que se aplique es cuestionable, puesto que el mérito de someter la decisión de los procedimientos de sanción a la deliberación de un cuerpo colegiado pierde sentido si ella es dictada por menos de la mayoría de sus miembros.

Consideramos que resolver dicho cuestionamiento no exige necesariamente una modificación legal, pudiendo haberse salvado, por ejemplo, si el mismo Consejo hubiese establecido en su norma interna de funcionamiento ${ }^{63}$ que, al menos en los casos más graves, definidos por los montos de las multas o por las cancelaciones en los registros, las sanciones solo puedan ser impuestas con un quorum mínimo de 3 consejeros.

\subsubsection{Comparecencia ante los tribunales de control}

Se lamenta que no se haya previsto la posibilidad de que el fiscal pueda controvertir las decisiones del Consejo en aquellos casos en que este descarte la existencia de una infracción. Dicha posibilidad existe en Francia confiriendo al presidente del Colegio la posibilidad de apelar de las sanciones, independientemente de si las personas investigadas apelan o no ${ }^{64}$. La disyuntiva tampoco se plantea en Estados Unidos ni en Inglaterra dada la existencia de tribunales separados. En Chile, esta restricción tampoco se plantea cuando existe una verdadera separación orgánica entre quien investiga y quien sanciona, por ejemplo, en la Fiscalía Nacional Económica en relación con el Tribunal de la Libre Competencia.

\section{Consideraciones finales}

La Ley $N^{\circ} 21.000$ subsana de manera satisfactoria algunas de las críticas que antes se formulaban al procedimiento sancionatorio llevado a cabo por la SVS. Pero ello no significa en lo absoluto que esté exento de defectos en lo referido a la garantía de imparcialidad del regulador. Entre las críticas que se pueden formular hoy, en relación con la imparcialidad personal, nos parece que las más relevantes dicen relación con haber regulado las declaraciones de interés en función del régimen patrimonial pactado, y el haber restringido la declaración de las actividades profesionales, laborales, etc. a un período de 12 meses mientras que la obligación de abstención concierne relaciones de profesionales que hayan tenido lugar en los últimos dos años. En la misma línea habría sido saludable extender la obligación de abstención a los últimos 3 años, como hemos citado respecto del caso francés o bien haber recurrido a la técnica anglosajona, utilizada por lo demás, en las recomendaciones de la OCDE, de hacer uso de estándares o principios directores ambos caracterizados por formularse en términos generales que pueden dar lugar a distintas aplicaciones.

Lo anterior podría estimarse satisfecho si la saludable cláusula de apertura contenida en el Art. 16, es interpretada de tal forma que se admita que existe conflicto de interés aún cuando la situación que lo origina sea anterior al plazo de dos años. Sin embargo, hemos aceptado que la interpretación es discutible.

\footnotetext{
${ }^{62}$ Reiteremos que el Art. 16 de la Ley permite al comisionado afectado por una causal de abstención asistir a sesiones en se traten materias adicionales a la que lo implica, pero su asistencia no se considera para efecto de determinar el quórum necesario para la resolución de la materia o asunto en la que pudiera tener interés o estar involucrado. Esto podría disminuir aún más los quórums.

${ }^{63}$ Resolución Exenta $\mathrm{N}^{\circ} 02$, de 21 de diciembre de 2017.

${ }^{64}$ Article L. 621-30 CMF, art. 6 de la Loi n 2010-1249, du 2010.
} 
Igual de criticable nos parece el hecho de haber previsto la intervención del Consejo en la autorización al fiscal para que decrete medidas intrusivas, o la intervención del Consejo en la autorización de medidas de policía. En cuanto a la imposibilidad del fiscal de apelar la decisión del Consejo que rechace la aplicación de una sanción si bien demuestra que la separación de funciones no está acabada, ella no es tan relevante desde el punto de vista de la garantía de imparcialidad como garantía procesal porque ella no perjudica, por razones obvias, al no sancionado. Sin embargo, podríamos plantearnos que tal decisión frustre a terceros interesados, como podrían ser consumidores financieros afectados.

En efecto, si bien en este texto nos hemos situado desde la perspectiva de los derechos de los sujetos regulados como protagonistas de un procedimiento sancionatorio, no podemos olvidar que igual de legítimos son los intereses de aquellos que se ven perjudicados por los hechos que originan los procedimientos sancionatorios.

\section{BIBLIOGRAFÍA CITADA}

ANGEL, KARINE Y DEZEUSE, ERIC (2008): “Le décret N²008-293 du 2 septembre 2008 et l'avenir de la procédure de sanction de l'Autorité des marchés financiers", en: Revue droit bancaire et financier (enero-febrero), pp. 10-26.

AUTORITÉ DES MARCHÉS FINANCIERS (2009): “Communiqué de presse, 17 décembre 2009: "Réaction de l'Autorité des marchés financiers à la décision de sa commission des sanctions relative à l'affaire EADS". Disponible en: https://www.amf-france.org/Actualites/Communiques-depresse/AMF/annee_2009?docld=workspace\%3A\%2F\%2FSpacesStore\%2Fbd83ec26-954b-45b0bb98-a58404d18874 [visitado el 17 de octubre de 2018].

BALDWIN, ROBERT; CAVE, MARTIN Y LODGE, MARTIN (2012): Understanding Regulation: Theory, Strategy, and Practice, $2^{\text {a }}$ edición (New York, Oxford University Press).

BALDWIN, ROBERT Y MCCRUDDEN, CHRISTOPHER (1987): Regulation and Public Law (Law and Context) (Londres, Weidenfeld an Nicolson).

BORDALI SALAMANCA, ANDRÉS (2009): "El derecho fundamental a un tribunal independiente e imparcial en el ordenamiento jurídico chileno", en: Revista de Derecho de la Pontificia Universidad Católica de Valparaíso (Vol. XXXIII), pp. 263-302.

(2011): "Análisis crítico de la jurisprudencia del tribunal constitucional sobre el derecho a la tutela judicial”, en: Revista Chilena de Derecho (Vol. 38, № 2), pp. 311-337.

BÓRQUEZ, JUAN CARLOS FERRADA (2011): "Los procesos administrativos en el Derecho chileno", en: Revista de Derecho de la Pontificia Universidad Católica de Valparaíso (№ XXXVI), pp. 251-277.

CAMACHO CEPEDA, GLADYS (2007): "La legitimidad de la potestad administrativa sancionadora", en: Revista de Derecho Público (Vol. 69, №2), pp. 9-23. 
COMISIÓN DE REFORMA A LA REGULACIÓN Y SUPERVISIÓN FINANCIERA (S.F.): "Informe". Disponible en: http://www.hacienda.cl/mercado-de-capitales/reforma-a-la-regulacion-y-supervision.html [visitado el 14 de abril de 2018].

COMISIÓN ESPECIAL INVESTIGADORA DE LA CÁMARA DE DIPUTADOS (2010): "Informe de enero de 2010". Disponible en: https://www.camara.cl/sala/doc2.aspx?DOCID=1940 [visitado el 08 de junio de 2018].

CORDERO QUINZACARA, EDUARDO (2009): Vocabulaire Juridique (Paris, PUF).

(2012a): "El Derecho administrativo sancionador y su relación con el Derecho penal", en: Revista de Derecho (Vol. 25, № 2), pp. 131-157.

(2012b): "La Administración del Estado en Chile y el concepto de autonomía", en: AA.VV., La Contraloría General de la República. 85 años de vida institucional (1927-2012)(Santiago, Contraloría General de la República), pp. 15-33.

(2014): Derecho administrativo: bases y principios en el derecho chileno (Santiago, Legal Publishing/Thomson Reuters).

DE LA OLIVA SANTOS, ANDRÉS Y PALOMO VÉLEZ, DIEGO (2007): Proceso civil: Hacia una nueva justicia civil (Santiago, Editorial Jurídica de Chile).

DOMÉNECH PASCUAL, GABRIEL (2002): “La abstención en el procedimiento administrativo”, en: Climent, Juan y Baño, José María (Coords.), Nuevas perspectivas del régimen local: estudios en homenaje al profesor José Ma Boquera Oliver (Valencia, Tirant le Blanch), pp. 409-464.

DUFOUR, OLIVIA (2010): "La procédure de sanction de l'AMF achève sa révolution", en: Les petites affiches ( $\left.{ }^{\circ} 258\right)$, pp. 4-5.

FRISON-ROCHE, MARIE-ANNE (2009): "Le droit à un tribunal impartial”, en: Cabrillac, R. y Revet, Th. (Dirs.), Libertés et droits fondamentaux (Paris, Dalloz), pp. 499-508.

(2010): “QPC, autorités de concurrence et de régulation économique: implications institutionnelles, in Question prioritaire de constitutionnalité et droit des affaires". Disponible en: http://mafr.fr/media/attachments/2010/11/26/Prise_de_parole_Universite_du_Maine_25-112010.pdf [visitado el 8 de octubre de 2018].

550-559.

(2011): “Regulation versus Competition", en: The Journal of Regulation ( $\left.N^{\circ} 7, \mathrm{I}-1.30\right)$, pp.

GARCía PINO, GONZALO y CONTRERAS VÁSQUEZ, PABLO (2013): "El Derecho a la tutela judicial y al Debido Proceso en la jurisprudencia del Tribunal Constitucional Chileno", en: Estudios constitucionales (Vol. I1, № 2). Disponible en http://dx.doi.org/10.4067/S0718-52002013000200007 [visitado el 13 de junio de 2018]. 
GARCÍA, JOSÉ (2009): “¿'Inflación de Superintendencias?: Un diagnóstico crítico desde el derecho regulatorio", en: Actualidad Jurídica (№ 9, tomo I), pp. 327-372.

GARCíA, JOSÉ Y VERDUGO, SERGIO (2010): “De las superintendencias a las agencias regulatorias independientes en Chile: Aspectos constitucionales y de diseño regulatorio", en: Actualidad Jurídica (N²2), pp. 263-305.

GONTARD, THIERRY (2010): “L'impartialité est une exigence fondamentale”, en: Les petites affiches (№ 258), pp. 5-6.

GUYOMAR, MATHIAS (2001): "Le droit au juge indépendant et impartial en matière administrative. Le principe vu par le Conseil d'Etat", en: Actualité juridique droit administratif (20 juin), pp. 518-525.

IDOUX, PASCALE (2010): “Autorités administratives indépendantes et garanties procedurales", en: Revue Française Droit Administratif (septiembre-octubre), pp. 920-930.

JACOBZONE, STEPHANE (2005): "Independent Regulatory Agencies in OECD Countries: An Overview", en: OCDE Working Party on Regulatory Management and Reform, designing independent and accountable regulatory authorities for high quality regulation, pp. 72-100. Disponible en: http://www.oecd.org/regreform/regulatory-policy/35028836.pdf [visitado el 08 de agosto de 2019].

LARRAÍN, MATIAS (2012): "Notas al ultimo intento de reforma del sistema de supervisión financiera", en: Anuario de Derecho Público (№ 1), pp. 392-414.

LASSERRE CAPDEVILlE, JÉRÔME (2008): "Comentario a la sentencia de la Corte de Apelaciones de Paris, de 25 juin 2008", en: Bulletin Joly Bourse (Vol. 60, N 13), s/p.

(2010): "Modifications de la procédure de sanction de l'autorité des marchés financiers", en: Les petites affiches ( $\left.N^{\circ} 250\right)$, pp. 15-17.

LETELIER, RAÚl (2017): “Garantías penales y sanciones administrativas”, en: Política Criminal (Vol. 12, № 24), pp. 622-689.

MASCINDARO, DONATO; VEGA, ROSARIA Y QUINTYN, MARC (2011): "The Economic Crisis: Did Financial Supervision Matter?", en: Working Paper, WP/11/261 (Fondo Monetario Internacional). Disponible en: https://www.imf.org/external/pubs/ft/wp/2011/wp11261.pdf [visitado el 8 de junio de 2018].

MINISTERIO DE HACIENDA (2010): "Informe de comisión especial investigadora de la cámara de diputados". Disponible en: https://www.camara.cl/sala/doc2.aspx?DOCID=1940 [visitado el 8 de junio de 2018].

(2011): "Informe de la Comisión de Reforma a la Regulación y Supervisión Financiera". Disponible en: http://www.hacienda.cl/mercado-de-capitales/reforma-a-la-regulacion-ysupervision.html [visitado el 14 de abril de 2018]. 
(2015): "Informe del Grupo de trabajo para el fortalecimiento institucional del mercado de capitales. Informe de recomendaciones". Disponible en: http://www.hacienda.cl/mercado-decapitales/fortalecimiento-institucional-del/informe-con-propuestas-para-el.html [visitado el 23 de julio de 2018].

MORALES, DIEGO (2018): “Comisión para el mercado financiero: un cambio en la arquitectura de supervisión financiera en Chile”, en: Estudios Públicos (№ 150), pp. 75-125.

OECD (2017): "Guía para crear una cultura de independencia", en: Creating a Culture of Independence: Practical Guidance against Undue Influence, OECD Publishing, Paris. OECD, Recomendación del Consejo de la OCDE sobre integridad pública, 2003. Disponible en: https://www.oecd.org/gov/ethics/recomendacion-sobre-integridad-es.pdf [visitado el 20 de noviembre de 2018].

PALOMO VÉLEZ, DIEGO (2002): “Aportación de la convención americana de derechos humanos a la perspectiva chilena de la dogmática procesal del derecho a la tutela judicial. un apoyo en dos fallos: casos Barrios Altos y Castillo Petruzzi", en: Revista lus et Praxis (Vol. 8, № 2). Disponible en: http://dx.doi.org/10.4067/S0718-00122002000200009 [visitado el 01 de julio de 2016].

PRALUS-DUPUY, JOËLLE (2003): "Réflexions sur le pouvoir de sanction disciplinaire reconnu à certaines autorités administratives indépendantes", en: Revue Française Droit Administratif (mayo-junio), pp. 554-567.

RODRÍGUEZ VEGA, KARINE (2013): “Création du Conseil de régulation bancaire et financière et du risque systémique", en: Les petites affiches (№ 250), pp. 12-14.

ROETS, DAMIEN (1997): "Impartialité et justice pénale", en: Travaux de l'Institut de Sciences criminelles (Volumen XVIII), pp. 494.

ROMÁN CORDERO, CRISTIÁN (2007): "Los principios del derecho administrativo sancionador", en: Revista de Derecho Público (Vol. 69, Tomo II), pp. 24-35.

SECURITIES AND EXCHANGE COMMISSION (2015): “Order concerning additional submission and protective order". Disponible en: https://www.sec.gov/litigation/opinions/2015/ia-4103.pdf [Visitado el 06 de octubre de 2018].

SOTO KLOSS, EDUARDO (1998): “El derecho fundamental de acceso a la justicia (a propósito de requisitos de admisibilidad)", en: Revista Chilena de Derecho (número especial), pp. 273-278.

VALDIVIA, JOSÉ MIGUEL Y BLAKE, TOMAS (2015): "El decaimiento del procedimiento administrativo sancionador ante el derecho administrativo", en: Estudios Públicos (№ 138), pp. 93-135.

VALLEJO, RODRIGO Y GUILOFF, MATIAS (INÉDITO): Ni juez, ni parte: la potestad sancionadora de la administración y la metodología del derecho administrativo (inédito). 
VALPUESTA ARÍSTEGUI, RAÚL Y PÉREZ ARIAS, PABLO (2013): "Repertorio de Jurisprudencia Administrativa de la Ley № 19.880, Bases de los Procedimientos Administrativos que rigen los actos de los Órganos de la Administración del Estado". Disponible en: http://repositorio.uchile.cl/bitstream/handle/2250/116224/de36-

Valpuesta_Raul.pdf?sequence=1\&isAllowed=y [visitado el 17 de octubre de 2018].

VILLABLANCA, LUSITANIA (2011): “Organización del regulador de los mercados financieros. Derecho comparado", en: Actualidad Jurídica (№ 24), pp. 297-394.

(2015): "Las nuevas formas de regulación en el mercado financiero chileno", en: A.A.V.V., Estudios de Derecho Comercial (Santiago, Facultad de Derecho Universidad de Chile), pp. 85-99.

\section{JURISPRUDENCIA CITADA}

REQUERIMIENTO EN CONTRA DEL SEÑOR CLODOMIRO ALMEYDA MEDINA FORMULADO POR EL SEÑOR MINISTRO DEL INTERIOR POR INFRACCIÓN AL ARTÍCULO 8 DE LA CONSTITUCIÓN (1987): Tribunal Constitucional 21 de diciembre de 1987 (requerimiento), en: https://www.pjud.cl.

CORTE CONSTITUCIONAL DE COLOMBIA: sentencia T-081 de 28 de febrero de 1994, en: http://www.corteconstitucional.gov.co/relatoria/1994/t-081-94.htm.

COUR D'APPEL DE PARIS, 25 juin 2008, 1ère chambre - section $h$, en: https://www.legifrance.gouv.fr/affichJuriJudi.do?idTexte=JURITEXT000019784659.

SOLICITUD DE LA CORTE DE APELACIONES DE TALCA, para que se emita un pronunciamiento acerca de la eventual inaplicabilidad de los artículos 6, letra B № 3 y 6; 107 y 161 del Código Tributario, en causa Rol Corte № 60.928 y Rol № 60.025-01, caratulada Guido González Muñoz con Servicio de Impuestos Internos (2008): Tribunal Constitucional 26 de junio de 2008 (solicitud), en: https://jurisprudencia.vlex.cl/vid/-58941720.

SENTENCIA SOBRE EL PROYECTO DE LEY QUE MODIFICA LA LEY N 19.496, sobre Protección de los Derechos de los Consumidores, correspondiente al Boletín N 9.369-03 (2018): Tribunal Constitucional 18 de enero de 2018, en: https://jurisprudencia.vlex.cl/vid/701318209.

ROJAS Y SUPERINTENDENCIA DE SALUD (2018): Corte suprema 19 de noviembre de 2018 (apelación protección), en: https://suprema.pjud.cl/SITSUPPORWEB/InicioAplicacion.do.

\section{NORMAS JURÍDICAS CITADAS}

\section{CHILE}

DECRETO LEY № 1.552, Acta Constitucional № 3 de los Derechos y Deberes Constitucionales. Diario Oficial, 13 de septiembre de 1972. 
DECRETO LEY № 3538, crea la Superintendencia de Valores y Seguros. Diario Oficial, 23 de diciembre de 1980.

CONSTITUCIÓN POLÍTICA DE LA REPÚBLICA DE CHILE, de 1980.

LEY № 19.880 establece bases de los procedimientos administrativos que rigen los actos de los órganos de la administración del Estado. Diario Oficial, 29 de mayo de 2003.

LEY № 20.880 sobre probidad en la función pública y prevención de los conflictos de intereses. Diario Oficial, 5 de enero de 2016.

DFL N`10 fija la fecha de entrada en funcionamiento de la Comisión para el Mercado Financiero y la fecha de supresión de la Superintendencia de Valores y Seguros. Diario Oficial, 23 de febrero de 2017.

RESOLUCIÓN EXENTA N02. Comisión para el Mercado Financiero, de 21 de diciembre de 2017.

RESOLUCIÓN EXENTA N³22. Superintendencia de Valores y Seguros, 9 de junio de 2011.

\section{EXTRANJERAS}

LOI N²010-1249 de régulation bancaire et financière. 22 de octubre 2010

ECODE OF FEDERAL REGULATION (ECFR). Disponible en: https://ecfr.io.

SECURITIES EXCHANGE ACT. PUBLIC LAW 73-291, 73d Congress, H.R. 9323, 6 de junio de 1934.

\section{INTERNACIONALES}

DECLARACIÓN AMERICANA DE LOS DERECHOS Y DEBERES DEL HOMBRE. Aprobada en la Novena Conferencia Internacional Americana, Bogotá, Colombia, 1948.

DECLARACIÓN DE DERECHOS DEL HOMBRE Y DEL CIUDADANO, de 1789.

PACTO DE SAN JOSÉ, COSTA RICA. 7 al 22 de noviembre de 1969. 